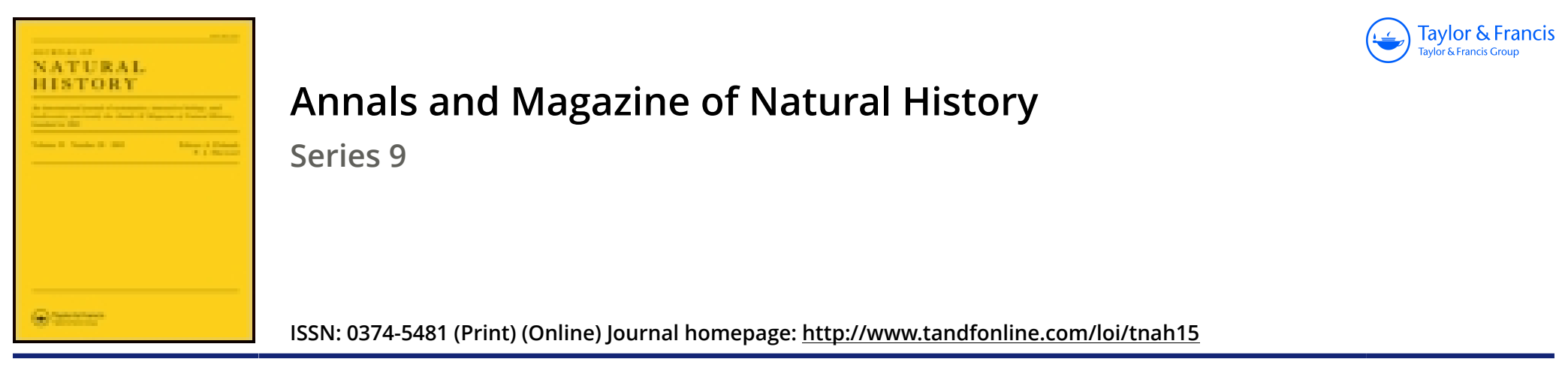

\title{
XXVIII.-A short description of the genitalia of (Ancistrocephalus) polypteri, Leydig, 1853
}

\author{
A.J. Hesse B.Sc.
}

To cite this article: A.J. Hesse B.Sc. (1922) XXVIII._A short description of the genitalia of (Ancistrocephalus) polypteri, Leydig, 1853, Annals and Magazine of Natural History, 9:51, 255-259, DOI: $10.1080 / 00222932208632668$

To link to this article: http://dx.doi.org/10.1080/00222932208632668

册 Published online: 04 Sep 2009.

Submit your article to this journal $\sqsubset \pi$

Џ Article views: 3

Q View related articles 5

4 Citing articles: 1 View citing articles 진 
into the underlying tissue in a species of Centrolophus from deep water at the Cape, were found to lead into a network of wide dermal canals, extending over the body, and filled with a viscid oily substance. The Cape "butter-fish" -Stromateus capensis-is highly prized for its fine flavour, while the Centrolophus referred to produces some kind of sickness or gastric disturbance when eaten-facts which have been noted in other members of the Stromateidæ.

XXVIII.-A short Description of the Genitalia of (Ancistrocephalus) polypteri, Leydig, 1853. By A.J. Hesse, B.Sc.*

The Cestode Ancistrocephalus polypteri parasitic in the intestine of Polypterus bichir was found by Dr. Loydig of Würzberg in 1853. He described the scolex, but, as his specimens were either not mature or were the anterior portions of the Cestode, he was unable to give an account of the genitalia. No further account has since appeared. This description is made from material obtained from Professor Leiper's collection. The material was rather limited and preserved in formalin solution. There were present two different kinds of worms. Two were Cyclophyllids, and the rest, consisting of a few pieces of sexually mature proglottides, a few knotted segments, and two heads with about 9 to $15 \mathrm{~cm}$. of strobila, were used by me to give this description.

\section{External Appearance.}

The worms showed a dirty white colour in the preservingfluid. As the worms were not complete, a definite length cannot be given.

The scolex was about $1 \mathrm{~mm}$. long and $5 \mathrm{~mm}$. broad. Superficially it was club-shaped, with an anterior blunt and rounded margin.

There was present a crown of hooks in the form of four radiating groups. These were situated on four weil-marked ridges. Each group had six claw-like hooks connected by a web-like structure (fig. 1).

Between the ridges passed down four shallow grooves, which are probably sucking-grooves. These were not well developed at all.

* From the Helminthological Department, London School of Tropical Medicine. 
When viewed from the top the head resembled a cross, with the groups of hooks on the four corners.

The head was followed by a thin neck, the length of which varied in the two specimens. In one it was $2 \mathrm{~mm}$. in length,

Fig. 1.

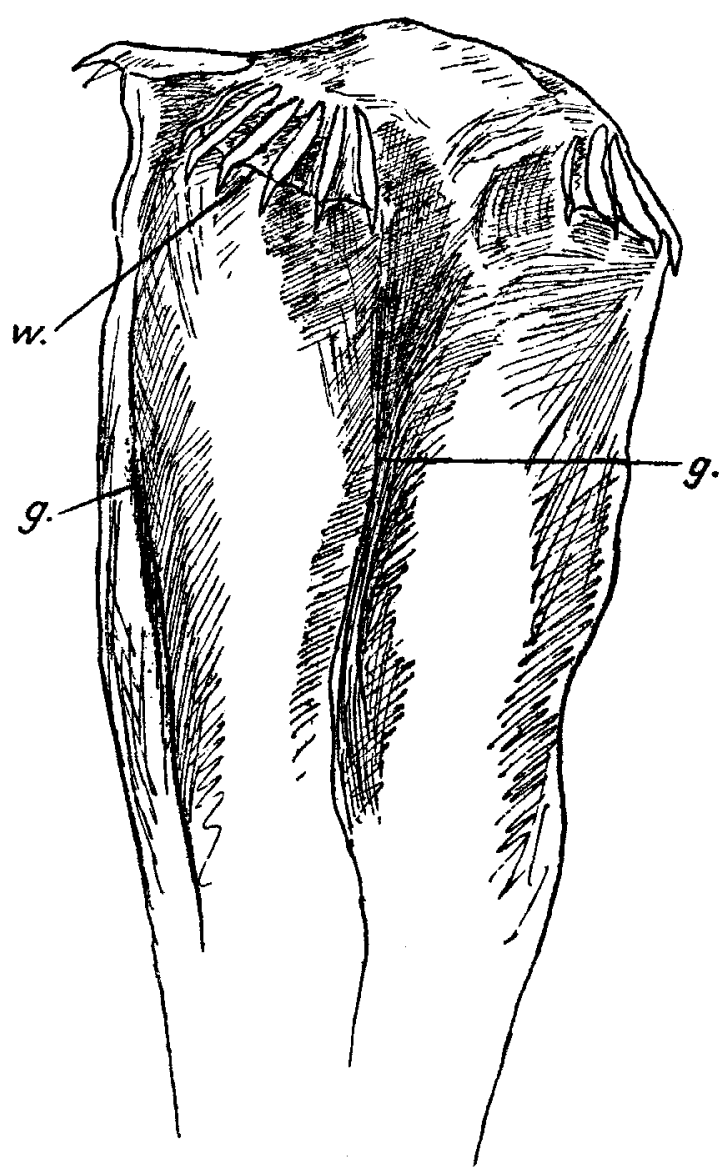

in the other it was shorter. Posterior to the neck followed a string of long, round, and thin segments resembling fine sewing-cotton. This stretch of segments was about $2 \cdot 5 \mathrm{~cm}$. long in one specimen. Still more posteriorly the segments broadened out-however, nowhere more than $2 \mathrm{~mm}$. (fig. 2 ). 
The chain, taken as a whole, showed certain peculiarities. Certain stretches of proglottides were narrow and long. These were followed by "island"-like broad stretches, where the segments were shorter and more numerous-two to three

Fig. 2.

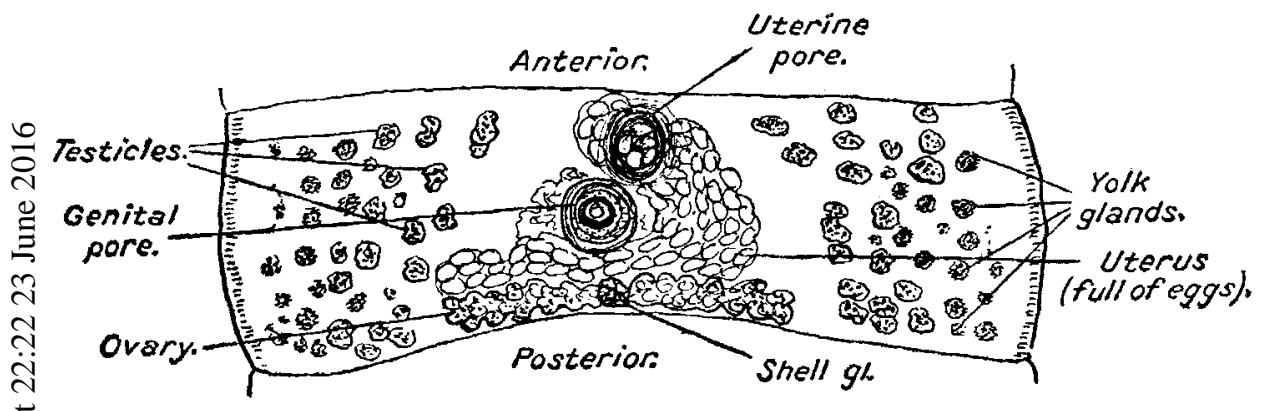

Fig. 3.

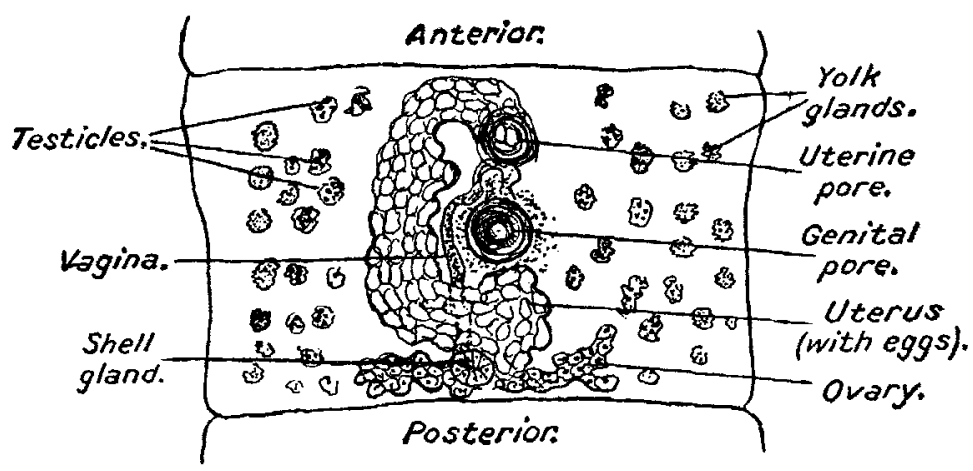

to the millimetre. Generally the segments were $1 \mathrm{~mm}$. long. In the "ripe" proglottides the dorsal surface was convex and the ventral flat-a condition brought about by the bulging uterus.

\section{Internal Anatomy.}

The specimens were stained in hæmatoxylin. A few transverse sections were made. In both cases, however, the greatly developed uterus obscured most of the structures. 
I was able, by examining several transverse sections, to construct a transverse section representing the position of the genitalia. In the figure the genital pore and ovary are, of course, not in the same plane, but put in for convenience' sake (fig. 3).

Fig. 4 .

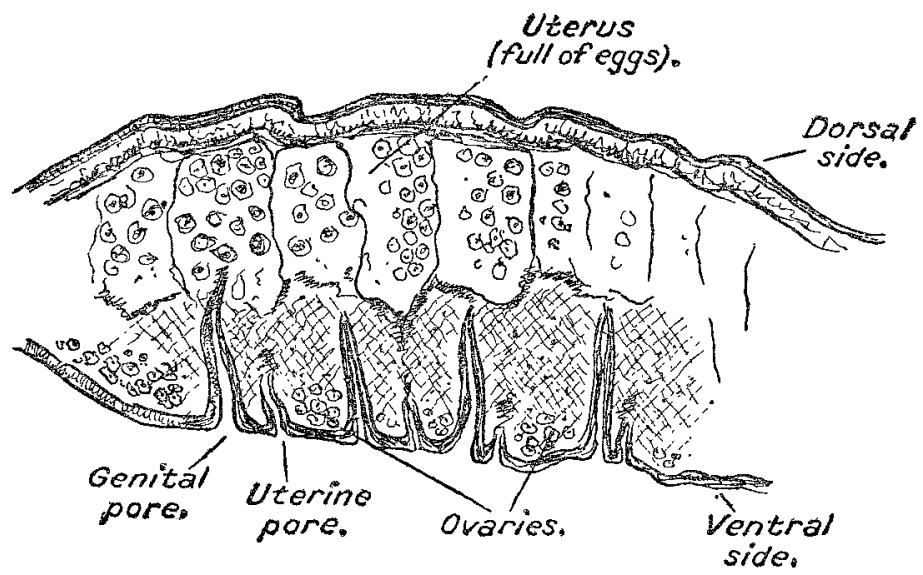

Fig. 5.

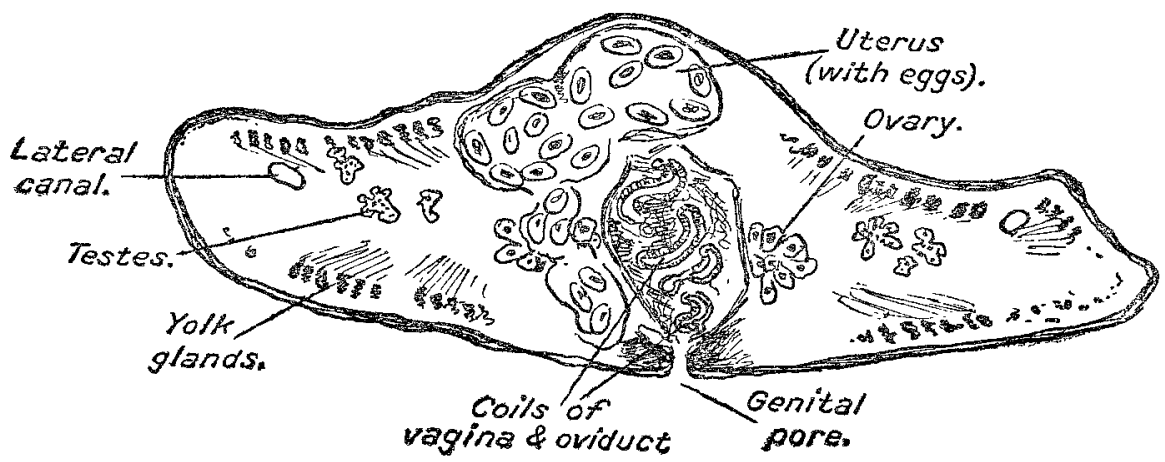

Testicles.-The testes were found to be distributed in the lateral regions of the segments, and more or less dorsally. I was not able to trace any ducts.

Ovary.-In every case the ovary was found to be situated at the posterior margin of each segment. It occupied a 
linear position, and was grapo-like. Near the middle of the ovary $\mathfrak{I}$ was able to identify a more darkly stained globular shell-gland. 'The ovary is medial, posterior, and ventral in each segment (fig. 4).

In a few segments I was able to trace a thick duct, which I believe to be the vagina. From the stained specimens nothing more was recognizable. From a few transverse sections indications of a coiled condition were visible (fig. 3 ).

The genital opening was ventral and median. The pore was surrounded by muscles, and the deeply stained area under it suggested a cirrus.

I found no separate opening for the vagina, so I concluded it opened together with the cirrus into a genital atrium (fig. 4).

Uterus.-The uterus appeared to be sac-like and distended. In every segment it was located more dorsally, causing a " bulging" of the dorsal surface.

It was situated, now on the right of the genital pore, with its convexity to the right, and now to the left, with the convexity to the left. This condition alternated irregularly. In nearly all my stained segments and transverse segments the uterus was distended and filled with eggs. In some of the stained segments the beginnings or "aulagen" of the utorus showed up as stained curves either to the right or to the left of the genital pore. There was a separate uterine pore in every ripe segment. This aperture was situated at the anterior portion on the ventral surface, and displaced slightly to the left or to the right of the genital pore and the median line-a condition depending upon the position of the uterus (Gig. 5).

\section{Vitelline Glands.}

These were confined to the lateral fields of the segments, and more or less in parallel rows. Transverse sections showed them to be sitnated near the dorsal and ventral surfaces respectively (fig. 4).

Lateral canals were visible as two longitudinal stained lines in the immature segments. In the sections they were not always visible, as they were small. In some they appeared laterally as two narrow ducts. I was unable to trace any transverse canals either in the stained segments or in the few sections.

Chalk bodies were visible, especially in the sections, as numerous refringent granules in the body-wall. 